\title{
SPOLM2O19
}

XIX SIMPÓSIO DE PESQUISA OPERACIONAL ELOGÍSTICA DA MARINHA

RIO DE JANEIRO, RJ, BRASIL - 06 A 08 DE NOVEMBRO DE 2019

\section{OTIMIZAÇÃO DA REDE DE TRANSPORTE DE SUPRIMENTOS DO EXÉRCITO BRASILEIRO NA REGIÃO DA AMAZÔNIA ORIENTAL}

\author{
Yuri Marinho de Carvalho \\ Instituto Militar de Engenharia \\ Praça Gen. Tibúrcio, 80 - Urca, Rio de Janeiro - RJ, 22290-270 \\ yuri.marinho@eb.mil.br \\ Orivalde Soares da Silva Júnior \\ Instituto Militar de Engenharia \\ Praça Gen. Tibúrcio, 80 - Urca, Rio de Janeiro - RJ, 22290-270 \\ orivalde@yahoo.com.br
}

\begin{abstract}
RESUMO
A análise estratégica do setor de transportes brasileiro aponta para a necessidade imperiosa de promover a eficiência do setor e ampliar a competitividade do país através da diminuição do Custo Brasil. Dentre as Regiões do Brasil, a Região Norte é a mais desprovida de infraestruturas viárias capazes de integrar os diversos setores da sociedade. Devido a capilaridade do Exército Brasileiro, presente em todos os rincões deste país, é sensível e premente a necessidade de otimização da rede de transportes na Região da Amazônia Oriental como forma de reduzir custos para a Força e para o Brasil. Este estudo aplicará um modelo matemático utilizando Programação Linear Inteira Mista de localização-alocação para apresentar uma análise de otimização da rede de transportes de gêneros alimentícios do $8^{\circ}$ Depósito de Suprimentos (D Sup), Órgão Provedor do Exército Brasileiro equiparado a um Centro de Distribuição no meio civil, responsável por suprir em diversas classes de materiais toda a região da Amazônia Oriental.
\end{abstract}

Palavra-chave: Transporte; Amazônia Oriental; Otimização; Localização; Alocação.

\begin{abstract}
The strategic analysis of the Brazilian transport sector points to promote the efficiency of the sector and increase the competitiveness of the country through the reduction of the Brazilian Cost. Among the Regions of Brazil, the Northern Region is the most devoid of road infrastructures capable of integrating the various sectors of society. Due to the capillarity of the Brazilian Army, present in all corners of this country, it is sensitive and urgent the need to optimize the transport network in the Eastern Amazon Region to reduce costs for the Force and for Brazil. This study will apply a mathematical model using Mixed Integer Linear Location-Allocation Programming to present an optimization analysis of the foodstuff transportation network of the 8th Supply Depot (D Sup), Logistic Organ of the Brazilian Army assimilated to a Distribution Center in the civil society, responsible for supplying the entire region of the Eastern Amazon in various classes of materials.
\end{abstract}


Keywords: Transport; Eastern Amazon; Optimization; Location; Allocation.

\section{Como Citar:}

CARVALHO, Yuri Marinho; SILVA JÚNIOR, Orivalde Soares da. Otimização da rede de transporte de suprimentos do Exército Brasileiro na região da Amazônia oriental. In: SIMPÓSIO DE PESQUISA OPERACIONAL E LOGÍSTICA DA MARINHA, 19., 2019, Rio de Janeiro, RJ. Anais [...]. Rio de Janeiro: Centro de Análises de Sistemas Navais, 2019.

\section{INTRODUÇÃO}

Desde os primórdios da humanidade, os alimentos não eram produzidos próximos aos locais de consumo e nem estavam disponíveis em todas as épocas do ano. Os nossos ancestrais não possuíam muitas alternativas a não ser consumi-los nos locais de produção ou armazená-los de forma primitiva para serem consumidos em uma melhor ocasião. Dessa forma, por não existirem sistemas mais complexos de transporte e armazenagem, os humanos se limitavam a levar somente o que podiam carregar e o prazo de armazenamento era extremamente curto. Esse sistema de transporte/ armazenagem obrigava-os a habitar regiões mais próximas as áreas de produção, bem como limitava a variedade de alimentos que poderiam ser consumidos.

O desenvolvimento dos sistemas logísticos aprimorou-se de forma lenta e gradual durante séculos, mas aperfeiçoou-se, em grande parte, com as atividades militares. A partir do fim da Segunda Guerra Mundial, as empresas notaram o quanto a logística influenciava nos custos operacionais e, desta forma, passaram a dedicar maior importância para este setor, com o intuito de diminuir despesas no transporte e na armazenagem.

No Brasil, o transporte enfrenta grandes limitações, sobretudo no modal rodoviário, que devido à falta de investimentos em infraestrutura e a uma fiscalização precária em relação as empresas vencedoras de certames licitatórios, possui grandes gargalos. Essas dificuldades acarretam na elevação do Custo Brasil que, consequentemente, é agregado ao valor dos produtos para os consumidores finais.

Logisticamente, o Exército Brasileiro desdobra-se através de 12 Regiões Militares (RM). O apoio logístico é realizado através de bases logísticas, ou seja, cada RM possui em sua estrutura Organizações Militares (OM) Logísticas, que são responsáveis por receber, controlar, armazenar e distribuir suprimentos para as OM localizadas na sua área de responsabilidade.

No caso específico da $8^{a}$ Região Militar, que apoia grande parte das Organizações Militares presentes na Amazônia Oriental, é imperiosa a execução de uma logística eficaz e efetiva como fator decisivo para a continuidade da atuação e da presença do Exército Brasileiro. Contudo, há na região uma malha viária precária, que prejudica econômica e socialmente o desenvolvimento da região, afetando a soberania nacional.

Desta maneira, resta considerarmos implícito o desafio de conceber uma logística na área de abrangência da $8^{\mathrm{a}} \mathrm{RM}$ capaz de ajustar-se à multiplicidade de situações de emprego, com suas nuances e especificidades, conforme prevê o Manual de Campanha EB70-MC10.238 - Logística Militar Terrestre (2018).

Dentre as Unidades logísticas subordinadas à $8^{\mathrm{a}} \mathrm{RM}$, o $8^{\circ}$ Depósito de Suprimento (D Sup) é o que movimenta maiores volumes financeiros e que abrange maior quantidade de Batalhões supridos. 
Para facilitarmos o entendimento da situação da área de apoio do $8^{\circ} \mathrm{D}$ Sup, temos que compreender as peculiaridades da região na qual ele está inserido, a Amazônia Legal. Esta localidade possui uma superfície de aproximadamente $5.217 .423 \mathrm{~km}^{2}$, o que corresponde a cerca de 61\% do território brasileiro. Ela é composta pelos Estados do Amazonas, Acre, Roraima, Rondônia, Mato Grosso, Amapá, Pará, Tocantins e pelos Municípios do Estado do Maranhão situados a oeste do Meridiano 44․ Ela é dividida em Amazônia Ocidental e Oriental. Conforme Decreto-Lei n 291 de 1967, ratificado pelo Decreto-Lei no 356 de 1968, a Amazônia Oriental, por exclusão, é composta pelos Estados do Pará, Maranhão, Amapá, Tocantins e Mato Grosso (IBGE, 2014).

A área total correspondente a Amazônia Oriental é de aproximadamente 2,9 milhões de $\mathrm{km}^{2}$ e possui uma população estimada em 21, 38 milhões de habitantes (IBGE, 2018), proporcionando uma baixa densidade demográfica em uma região altamente estratégica $(7,37$ hab $/ \mathrm{km}^{2}$ ), com uma importante Bacia Hidrográfica, um rico bioma amazônico que abriga o maior banco genético do planeta e um patrimônio mineral imensurável (densidade demográfica nacional estimada: $24,5 \mathrm{hab} / \mathrm{km}^{2}$ ).

Desta maneira, a situação das vias de transporte na região também é posta em segundo plano devido a reduzida ocupação populacional. Portanto, tendo em vista a inviabilidade de tráfego em diversos trechos rodoviários e aquaviários, este estudo utilizou-se do modelo matemático de Programação Linear Inteira Mista de localização-alocação de $P$ Mediana para verificar, dentre as cidades que já possuem Organizações Militares, qual seria a mais propícia para ser alocado um Depósito de Suprimento, de forma a minimizar as distâncias e diminuir as rupturas e atrasos de fornecimento. Para isso, foram consideradas as distâncias entre todos os pontos de apoio e a quantidade de Batalhões em cada cidade que necessitará ser suprida. Para testar a adequação do modelo, experimentos computacionais foram efetuados restringindo a nova localização do D Sup às cidades que já possuem infraestrutura militar instalada.

Cabe mencionar a Portaria ${ }^{\circ}$ 019, do Estado Maior do Exército, de 27 de janeiro de 2016 - Diretriz para otimizar a Logística no Comando Militar da Amazônia, no Comando Militar do Norte e no Comando Militar do Oeste (EB20-D-03.001), que estabeleceu objetivos de caráter administrativo, logístico, doutrinário e operativo relativas à otimização da logística no âmbito desses Comandos Militares de Área.

Dentre os objetivos traçados, este documento contempla o aumento da capacidade de armazenagem dos depósitos, unificação e padronização de cargas, modernização da frota de embarcações aquaviárias, aumento de efetivo. O presente trabalho corrobora com as diretrizes e metas estabelecidas, de forma que estas implementações trarão significativa economia para os cofres públicos e para o Exército Brasileiro.

A Estratégia Nacional de Defesa (END) tem em suas diretrizes priorizar a região amazônica por ela representar um dos focos de maior interesse na agenda ambientalista mundial. A END menciona que a defesa da Amazônia exige a implementação de um projeto de desenvolvimento sustentável que passe pelo trinômio: monitoramento/controle, mobilidade e presença.

Neste viés, o trabalho será delimitado em quatro seções adicionais. Na seção 2 será realizado um extrato da atual situação viária e logística de cobertura do $8^{\circ}$ Depósito de Suprimento. Na seção 3 será incluído restrições e condições para o método de análise utilizado. Em seguida, na seção 4, serão analisados os resultados computacionais obtidos. Por fim, na seção 5 serão descritas as conclusões e as oportunidades de aprimoramento para trabalhos futuros do modelo matemático aqui exposto. 


\section{SITUAÇÃO LOGÍSTICA DA ÁREA DE COBERTURA DO $8^{\circ}$ DEPÓSITO DE SUPRIMENTO}

Apesar das grandes riquezas da floresta tropical da Amazônia Oriental e da sua agricultura, a infraestrutura logística, principalmente a situação viária de transportes, encontra-se defasada em relação às necessidades do Brasil, apresentando-se como um desafio a ser transporto para que as atividades logísticas possam ser eficazes.

O Manual de Logística Militar Terrestre do Exército Brasileiro (EB70-MC-10.238, 2018) reconhece no transporte o instrumento indispensável para o ciclo logístico, que "envolve, em uma visão ampla, o capital humano, a infraestrutura física, as organizações, os sistemas e os equipamentos necessários ao cumprimento da missão das forças apoiadas.”

A função logística de transporte é afetada, sobremaneira, pela qualidade das vias da região devido a diversos fatores, como enorme tráfego de caminhões com sobrecarga, chuvas constantes, variação da trafegabilidade dos rios e falta de sinalização aquaviária.

O sistema fluvial da Região Hidrográfica da Amazônia pode ser classificado, segundo Bertani (2015), como um sistema de rios de predomínio meandrante, em que se tem, comumente, a presença de planícies de inundação que podem conter um complexo de vários subambientes deposicionais. Estes ambientes, influenciados pelo regime de chuva, apresentam obstáculos para a navegação.

Embora a navegação aquaviária seja o modal mais apropriado para a região Norte, ainda carece de infraestrutura para tornar os rios mais profundos e navegáveis durante todo o ano. E ainda, conforme Caderno Setorial de Recursos Hídricos, do Ministério do Meio Ambiente (2006), a navegação monitorada pelos organismos competentes se constitui como o melhor meio de controle e fiscalização das águas e áreas ribeirinhas, contribuindo para a prevenção contra os assoreamentos dos rios e para a defesa da soberania nacional.

Os problemas se acentuam quando nos referimos aos modais terrestres, obrigando ao operador logístico utilizar com maior frequência outros modais para o transporte de suprimento e de pessoal, aumentando os custos e o tempo de transporte na região.

O $8^{\circ} \mathrm{D}$ Sup abrange logisticamente toda a Amazônia Oriental. O apoio é prestado pelos modos fluvial e rodoviário. Ele é responsável pela logística em 18 cidades, sendo que os mais importantes adensamentos populacionais da área de apoio logístico estão presentes nas cidades de Belém-PA, Marabá-PA, Santarém-PA, Itaituba-PA, Altamira-PA, Macapá-AP, São Luís-MA e Imperatriz-MA, sedes de batalhões do Exército que serão objetos de análise deste estudo.

\subsection{A AMAZÔNIA ORIENTAL E A INFRAESTRUTURA LOGÍSTICA MILITAR.}

A maior capacidade ociosa dos modais de transporte na Amazônia Orienta encontrase no modal hidroviário. A região apresenta diversos rios com potencial para se transformarem em hidrovias capazes de escoar grande parte da produção brasileira de grãos, derivados de petróleo e minérios.

Contudo, apesar da grande malha de rios existentes, as inconclusivas obras e serviços de manutenção diminuem as condições de navegabilidade e de capacidade de transporte, tornando este modal inviável para o planejador logístico em grande parte da área de apoio logístico do $8^{\circ} \mathrm{D}$ Sup. A inconstância dos níveis de água, períodos de chuvas, falta de sinalização, fazem com que a trafegabilidade se torne intermitente. Somando-se a estes fatores, foi verificado por Pitz et al. (2017) que a ociosidade da capacidade de carga durante os transportes nas embarcações fluviais utilizadas pelo $8^{\circ}$ D Sup acarretam em uma elevação 
de custo anormal, fazendo com que o custo aquaviário na região se torne mais caro do que o rodoviário para o Exército Brasileiro. Desta maneira, para evitar o atraso ou a ruptura de fornecimento e na tentativa de utilizar o modal com menor custo, analisaremos as distâncias entre as cidades pelo modal rodoviário.

Segundo o atlas de manutenção rodoviária do DNIT (2019) as principais rodovias da Amazônia Oriental possuem trechos com necessidade de intervenção. A BR-230 é uma importante rodovia que integra de oeste a leste o Estado do Pará. Situada entre o Estreito (MA) e Humaitá (AM), com extensão de $2.982 \mathrm{~km}$. Este traçado tem grande relevância para a logística da região, pois tem capacidade para ser a principal alimentadora intermodal, integrando os afluentes Sul do Rio Amazonas com as cidades de Marabá, Almira, Itaituba e Humaitá, localizadas, respectivamente, nos rios Tocantins, Xingu, Tapajós e Madeira. Além disso, é de suma importância para a logística militar, pois pode ser empregada como principal via de acesso para suprimento e tropas da região Norte e Nordeste.

A rodovia BR-163 é de grande importância para o desenvolvimento, tendo em vista o alto potencial econômico que ela traria caso estivesse em condições de escoar as riquezas do Centro-Oeste do Brasil em direção do porto de Santarém. Tem uma extensão de 1.743 km, com 760 km no estado do Mato Grosso. Com relação a logística militar, é fundamental para o desenvolvimento de ações militares vindas do Sul e do Sudeste do país. Além de possibilitar a integração através da hidrovia Tapajós - Teles Pires do Comando Militar do Oeste com o Comando Militar do Amazônia e com o do Norte.

No Estado do Amapá, a principal rodovia é a BR-156, que se encontra em situação precária em grande parte do trajeto. Diversos trechos não estão pavimentados e há poucas ligações com terminais de outro modais.

Analisadas as vias rodoviárias as quais poderão ser transportados os suprimentos, nos resta definir as cidades e respectivas Organizações Militares que são apoiadas pelo $8^{\circ} \mathrm{D}$ Sup e que serão realizadas as iterações. De acordo com o volume transporte e a sua representatividade, Pitz et al. (2017) definiu-as como as seguintes:

- Belém: Comando Militar do Norte, Comando da $8^{a}$ Região Militar, $2^{\circ}$ Batalhão de Infantaria de Selva, Parque Regional de Manutenção da $8^{\circ} \mathrm{RM}, 15^{\mathrm{a}}$ Companhia de Polícia do Exército, $28^{\mathrm{a}}$ Circunscrição de Serviço Militar, $41^{\circ}$ Centro de Telemática, $8^{\mathrm{a}}$ Inspetoria de Contabilidade e Finanças do Exército e $8^{\circ}$ Depósito de Suprimento (como unidade).

- Marabá: Comando da 23a Brigada de Infantaria de Selva, 23a Companhia de Comunicações de Selva, 33 Pelotão de Polícia do Exército, Hospital de Guarnição de Marabá, $52^{\circ}$ Batalhão de Infantaria de Selva, $1^{\circ}$ Grupamento de Artilharia de Campanha de selva e $23^{\circ}$ Batalhão Logístico de Selva.

- Tucuruí: 23 Esquadrão de Cavalaria de Selva

- Santarém: $8^{\circ}$ Batalhão de Engenharia de Construção

- Altamira: $51^{\circ}$ Batalhão de Infantaria de Selva

- Itaituba: $53^{\circ}$ Batalhão de Infantaria de Selva

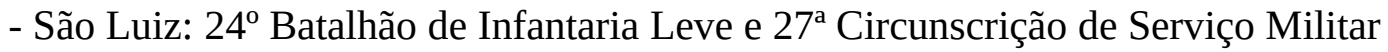

- Imperatriz: $50^{\circ}$ Batalhão de Infantaria de Selva

Além dessas, existem os Batalhões do Estado do Amapá. Contudo, como o transporte para Macapá é inviável por meio rodoviário, o 34 Batalhão de Infantaria de Selva 
será incluído como Batalhão pertencente à guarnição da instalação da facilidade, que deverá apoiá-lo por modal aquaviário;

Assim sendo, montamos a Tabela 1 da ponderação do fator variável que determina a quantidade de transporte que deve ser realizado de acordo com a quantidade de Unidades Militares. Quanto maior o fator, maior será a quantidade de Unidades em uma guarnição, o que corresponde a necessidade de maiores comboios logísticos ou a mais viagens para que aquela guarnição seja suprida.

Tabela 1 - Ponderação das Guarnições por quantidade de OM.

\begin{tabular}{|l|c|c|c|c|}
\hline \multicolumn{1}{|c|}{ Guarnição } & $\begin{array}{c}\text { Quantidade de } \\
\text { Unidades } \\
(\mathrm{x} 1)\end{array}$ & $\begin{array}{c}\text { Quantidade de } \\
\text { Subunidades/ Grande } \\
\text { Comando (x0,25) }\end{array}$ & $\begin{array}{c}\text { Quantidade de } \\
\text { pelotões } \\
(\mathrm{x} 0,08)\end{array}$ & Total \\
\hline Belém-PA & 4 & 5 & 0 & 5,25 \\
\hline Santarém-PA & 1 & 0 & 0 & 1 \\
\hline Itaituba-PA & 1 & 0 & 0 & 1 \\
\hline Altamira-PA & 1 & 0 & 0 & 1 \\
\hline Marabá-PA & 4 & 2 & 1 & 4,58 \\
\hline Tucuruí-PA & 0 & 1 & 0 & 0,25 \\
\hline Imperatriz- MA & 1 & 0 & 0 & 1 \\
\hline São Luís- MA & 1 & 1 & 0 & 1,25 \\
\hline
\end{tabular}

Elaboração: próprio autor.

As Organizações Militares que são caracterizadas no site do Exército Brasileiro (2019) como Unidades, receberam 1 ponto. As que são caracterizadas como Subunidades ou Grandes Comandos receberam 0,25. Isto porque o previsto para cada Batalhão é aproximadamente 4 vezes o valor de uma Subunidade/ Grande Comando. Para cada Subunidade, são previstos 3 pelotões. Portanto, o peso dos pelotões foram de 0,08 .

Após esta ponderação, foi estabelecido a matriz entre todas as cidades passíveis de ser instalado a facilidade, exposta na Tabela 2. As distâncias foram dispostas em quilômetro.

Tabela 2. Matriz de distância entre cidades.

\begin{tabular}{|lc|c|c|c|c|c|c|c|c|}
\hline $\begin{array}{l}\text { Distâncias entre } \\
\text { cidades - em KM. }\end{array}$ & $(1)$ & $(2)$ & $(3)$ & $(4)$ & (5) & (6) & (7) & (8) \\
\hline Belém-PA & $(1)$ & 0 & 1384 & 1315 & 827 & 553 & 456 & 594 & 792 \\
\hline Santarém-PA & $(2)$ & 1384 & 0 & 369 & 557 & 881 & 950 & 1291 & 1861 \\
\hline Itaituba-PA & $(3)$ & 1315 & 369 & 0 & 488 & 988 & 881 & 1221 & 1792 \\
\hline Altamira-PA & $(4)$ & 827 & 557 & 488 & 0 & 500 & 393 & 734 & 1304 \\
\hline Marabá-PA & $(5)$ & 553 & 881 & 988 & 500 & 0 & 251 & 234 & 805 \\
\hline Tucuruí-PA & $(6)$ & 56 & 950 & 881 & 393 & 251 & 0 & 482 & 993 \\
\hline Imperatriz - MA & $(7)$ & 594 & 1291 & 1221 & 734 & 234 & 482 & 0 & 630 \\
\hline São Luís - MA & $(8)$ & 792 & 1861 & 1792 & 1304 & 805 & 993 & 630 & 0 \\
\hline
\end{tabular}

Fonte: elaborado pelo próprio autor.

\section{MODELAGEM MATEMÁTICA DO PROBLEMA DE LOCALIZAÇÃO}


Com base no modelo desenvolvido por Pitz et al. (2017) e nos parâmetros utilizados por eles, será proposto um modelo que respeite as demandas por quantidade de apoio necessário e que minimize a distância média percorrida nos transportes realizados pelo $8^{\circ} \mathrm{D}$ Sup. Estas, por sua vez, aparecem identificadas nas matrizes de origem-destino de carga criada com base nas cidades com maior adensamento populacional. A partir desta análise, será realizado um levantamento da melhor localização para o depósito que o aproxime de todos as Organizações Militares a serem supridas.

Ou seja, se um determinado produto deve deixar a cidade de origem e chegar a um Batalhão em específico, existe então uma relação biunívoca entre o que é enviado e o que é recebido, não sendo permitidas alterações de cargas ou de rotas ao longo do trajeto. O intuito é que (1) a Organização no destino final seja atendida dentro do prazo e dentro da sua necessidade; (2) como há um alto grau de dependência entre os Batalhões e os Depósitos devido a normas para aquisições internas do Exército, é necessário que o $8^{\circ} \mathrm{D}$ Sup satisfaça a demanda necessária para que não seja prejudicada a operacionalidade dos Batalhões; (3) seja reduzido custos com transportes; e (4) para que verifiquemos se, dentro da $8^{a}$ Região Militar, a localização atual do $8^{\circ} \mathrm{D}$ Sup é a mais econômica. Destaca-se ainda que, como o escopo do trabalho é verificar se a atual localização do $8^{\circ} \mathrm{D}$ Sup é a mais viável, não foram considerados fluxos com Intermediários Logísticos.

Para descrever o modelo, seja um conjunto $I$ de cidades candidatas para abertura da facilidade e um conjunto $J$ de cidades de destino, obtém-se os seguintes parâmetros:

\section{Índices}

\begin{tabular}{|ll}
\hline$i$ & Índice das cidades de origem, $\mathrm{i}=1, \ldots, \mathrm{I}$ \\
\hline$j$ & Índice das cidades de destino, $\mathrm{j}=1, \ldots, \mathrm{J}$ \\
\hline
\end{tabular}

\section{Variáveis}

$\chi_{i j}$ Variável de decisão que representa a fração da demanda $i$ atendida pela instalação $j$.

$y_{i}$ Variável binária que irá afirmar se a facilidade será (1) ou não (0) instalada na cidade de origem $i$.

\section{Parâmetros}

\begin{tabular}{|ll|}
\hline$W_{i}$ & Quantidade de Organizações Militares em $j$ \\
\hline$d_{i j}$ & Distância entre as cidades $i$ e $j$ \\
\hline$P$ & Quantidade de facilidades \\
\hline
\end{tabular}

A Função Objetivo (1) minimiza as distâncias média de transporte, considerando a quantidade de quartéis em cada cidade $\left(w_{J}\right)$ como fator multiplicador para a quantidade de apoio a ser prestado.

Minimizar $\mathrm{z}=\sum_{i} \sum_{j} w_{j} d_{i j} x_{i j}$ 


$$
\begin{aligned}
& \sum_{j} x_{i j}=1, \forall i \in I \\
& \sum_{i} y_{i}=P \\
& x_{i j} \leq y_{i} \forall i \in I, \forall j \in J \\
& x_{i j}, y_{i} \in\{0,1\}
\end{aligned}
$$

As restrições (2) são binárias e limitam a origem do depósito a um. As restrições (3) indicam que só será criado " $P$ " facilidade (s). As restrições (4) garantem que as distâncias entre as cidades que não forem escolhidas serão zeradas para o cálculo da distância mínima. As demais restrições (5) estão relacionadas ao domínio de definição das variáveis.

\section{ANÁLISE DOS RESULTADOS OBTIDOS}

Através do software AIMMS, foi realizado uma entrada de dados relativa ao modelo matemático descrito na seção 3 e ao estudo de caso descrito na seção 2. Deste processo, encontrou-se a seguinte localidade para a instalação da facilidade:

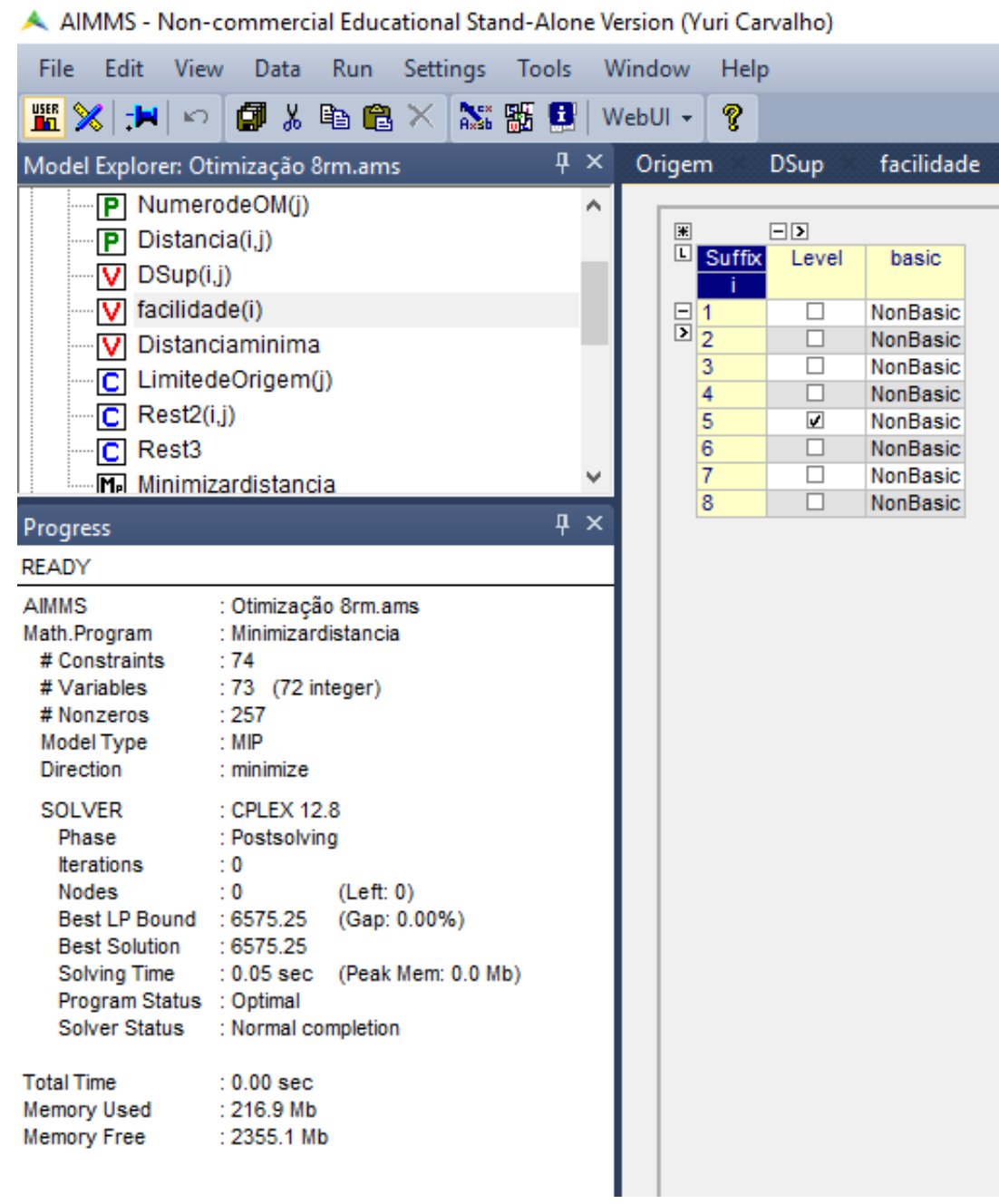

Figura 1 - Resultado otimização no AIMMS

Fonte: Imagem obtida no software AIMMS pelo próprio autor. 
Observa-se que a cidade selecionada para a instalação da facilidade foi Marabá, diferentemente da atual Belém, onde localiza-se o D Sup. A distância total de apoio gerado foi de $6574,25 \mathrm{~km}$ para suprir as demandas uma única vez em todas as outras sete cidades.

Contudo, a facilidade instalada em Marabá deverá ser capaz de apoiar por modal hidroviário Macapá. Como o Rio Tocantins é navegável e permite que embarcações cheguem até Macapá, essa possibilidade se mostra viável.

Além disso, para cálculos comparativos, ao multiplicarmos o fator ponderador da cidade de Belém por um número muito grande, de forma a desequilibrar a função e ela ser escolhida, verificamos que o percurso que ela executaria seria $17,96 \%$ maior.

Pitz et al. (2017) verificou que o $8^{\circ}$ D Sup realiza 6 apoios anuais. Desta forma, a economia de custo de transporte acumulada seria de aproximadamente $107 \%$ ao ano, ao trocarmos a cidade de Belém por Marabá.

Corroborando com esta economia inclui-se o fato de que o abastecimento do D Sup em algumas classes de materiais (como munição, fardamento, entre outros) é originária da Base de Apoio Logístico do Exército, no Rio de Janeiro. Ao chegar na Amazônia Oriental, atualmente o comboio originário da região Sudeste comete um erro crasso ao atravessar o Estado do Pará até o $8^{\circ} \mathrm{D}$ Sup (que se localiza em Belém). Após os processos contábeis e escriturais de armazenamento, o suprimento é distribuído pelas localidades situadas mais ao sul da região, caracterizando um transporte para a retaguarda. Portanto, ao substituir a localização do Depósito de Suprimento para a cidade de Marabá, também seria otimizado o custo de transporte que é destinado ao depósito.

Por fim, caso fosse possível instalar duas facilidades, ou seja, um depósito e um cross-docking, as cidades de Belém e Marabá seriam selecionadas e a distância total percorrida seria de $3.655,75 \mathrm{~km}$, mais de $110 \%$ de economia por rodada de entrega (comparando com o modelo atual). Diante da estrutura organizacional do Exército Brasileiro, para diminuir custos, o recomendável seria que o depósito se mantivesse em Belém e que a guarnição de Marabá funcione como cross-docking.

\section{CONCLUSÕES E OPORTUNIDADES DE APRIMORAMENTO}

Para contrapor-se às ameaças à Amazônia, é necessário fortalecer a presença militar, incrementar a participação do Estado no desenvolvimento sustentável, visando a defesa das riquezas naturais.

Portanto, foi verificado que ainda há muito a ser otimizado no que tange a cadeia de suprimento na região da Amazônia Oriental. As malhas viárias não estão em condições ideais para o planejamento de frotas e para o transporte, elevando significativamente os custos dos produtos que transitam pela região.

Foi verificado que para diminuir os custos dos transportes, a melhor localização para o Depósito de Suprimento que apoiará a região da Amazônia Oriental é na cidade de Marabá - PA. Os custos médios de transporte encontrados através do método de cálculo conhecido como "P-mediana" indicaram que esta cidade possui a melhor localização para os transportes rodoviários, que segundo Pitz et al. (2017), dentre os modais disponíveis para a 8a RM, foi o mais econômico para o Exército Brasileiro em 2015.

Como oportunidade de estudos futuros, poderia ser verificado o custo de transporte da Base de Apoio Logístico do Exército para a cidade de Belém para que seja mensurado se a implantação da cabotagem em Belém torná-la-ia mais vantajosa do que atravessar o Brasil pelo modal rodoviário, aplicando esta diferença de custo em uma análise de sensibilidade do modelo aqui proposto.

E ainda, no mês de fevereiro foi realizado pelo Ministério Público uma audiência pública para discutir o projeto de dragagem e derrocamento no chamado Pedral do Lourenço, 
no rio Tocantins. Esta obra tornará Marabá uma cidade com grande eficiência aquaviária, capaz de atender a maioria das principais Organizações Militares subordinadas a $8^{\text {a }}$ Região Militar, consolidando a hipótese de melhor localidade para a implantação de um centro de distribuição.

\section{REFERÊNCIAS BIBLIOGRÁFICAS}

[1] BERTANI, T. C. Sensoriamento Remoto e caracterização morfológica no Baixo Rio Solimões, com análise de suas rias fluviais. Tese de Doutorado. Instituto Nacional de Pesquisas Espaciais (INPE), 2015. Disponível em <http://urlib.net/8JMKD3MGP3W34P/3L46AM8>. Acesso em 15 de maio de 2019.

[2] BRASIL. Exército Brasileiro. Documento Interno do Exército $\mathbf{n}^{\mathbf{0}}$ 087-Ass G EM Esp Cmdo $8^{\text {a }}$ RM, para o IME. 14 set. 16. 16p. $8^{a}$ Região Militar, Belém.

[3] BRASIL. Exército Brasileiro (2019). Quartéis por Estado. Disponível em:<http://www.eb.mil.br/quarteis-por-estado1>. Acesso em 15 de maio de 2019.

[4] BRASIL. Exército Brasileiro. Documento Interno do Exército n 698 Ch COS, para a $8^{\text {a }}$ RM. 6 set. 16. 7p. $8^{\circ}$ Depósito de Suprimento, Exército Brasileiro, Belém. Brasil. Fluxo de Apoio Logístico da $8^{a}$ Região Militar. 22 jul. 16. 6p. $8^{a}$ Região Militar, Belém.

[5] BRASIL. Exército Brasileiro. Manual de Campanha: Logística Militar Terrestre. EB70-MC-10.238. $1^{a}$ ed. Brasília: Ministério da Defesa, Exército Brasileiro, 2018. 115p.

[6] BRASIL. Exército. Portaria n ${ }^{0} 019$ - Estado-Maior do Exército, de 27 de janeiro de 2016. Aprova a Diretriz para otimizar a logística no Comando Militar da Amazônia (CMA), no Comando Militar do Norte (CMN) e no Comando Militar do Oeste (CMO) (EB20-D-03.001), Boletim do Exército, Brasília, DF, n 05, p 23, 05 fev.2016.

[7] BRASIL. Ministério da Defesa. Estratégia Nacional de Defesa (2012). Disponível em:<https://www.defesa.gov.br/arquivos/estado_e_defesa/END-PND_Optimized.pdf $>$. Acesso em 15 de maio de 2019.

[8] BRASIL. Ministério do Meio Ambiente. Caderno Setorial de Recursos Hídricos: Saneamento (2006).

Disponível em:<http://www.mma.gov.br/estruturas/161/_publicacao/161_publicacao230220110316 57.pdf $>$. Acesso em 15 de maio de 2019.

[9] CAMPOS, C. D. Transporte logístico fluvial na Amazônia ocidental - uma proposta de condicionantes operacionais e doutrinárias para a configuração mais adequada das balsas empregadas pelo centro de embarcações do comando militar da Amazônia. Dissertação de mestrado. Escola de Aperfeiçoamento de Oficiais (2017). Disponível em <http://www.bdex.eb.mil.br/jspui/handle/1/1119>. Acesso em 15 de maio de 2019.

[10] DNIT. Departamento Nacional de Infraestrutura do Transporte (2019). Mapas de Gerenciamento de Rodovias. Disponível em <https://www.dnit.gov.br/rodovias/mapade-gerenciamento/mapa-de-gerenciamento>. Acesso em 15 de maio de 2019.

[11] IBGE. Instituto Brasileiro de Geografia e Estatística (2014). Amazônia Legal 1:250.000. Disponível em:< https://www.ibge.gov.br/geociencias/informacoesambientais/vegetacao/15819-amazonia-legal.html?=\&t=o-que-e $>$. Acesso em 15 de maio de 2019.

[12] IBGE. Instituto Brasileiro de Geografia e Estatística (2018). Cidades e Estados. Disponível em:< https://www.ibge.gov.br/cidades-e-estados.html>. Acesso em 15 de 
maio de 2019.

[13] ILOS. Instituto ILOS (2016). Custos logísticos. Disponível em:<http://www.ilos.com.br/web/analise-de-mercado/relatorios-de-pesquisa/custoslogisticos-no-brasil/> . Acesso em 15 de maio de 2019.

[14] PITZ, I. B.; FIACO, R. M. D.; DINIZ, M. V.; LOPES, L. A. S.; BANDEIRA, R. A. M.; BANDEIRA, A. P. F. Cadeia de Distribuição de Suprimentos Militares na Amazônia Oriental (2017). Anais do XXXI Congresso Nacional de Pesquisa em Transporte da ANPET. Recife. 13p.

[15] SANTOS, A. D. N. A Influência da Infraestrutura Logística da Amazônia Oriental para o Dimensionamento do Grupo Funcional Transporte. Revista Científica da ECEME - PADECEME, v.8, n.16, p.95-108, Rio de Janeiro, RJ, 2016. 